Lesbianism-A Study of Female Homosexuality by David H. Rosen. Springfield, 1974, Illinois, Charles C. Thomas. $\$ 4.95$ paper, $\$ 7.95$ cloth.

This monograph is a detailed study of a small sample of 26 non-patient lesbians. As the author states, this area of sexual behaviour has been neglected. There are few studies on female homosexuality compared with the numerous reports on male homosexuality. Possibly the reason for this is that lesbianism generates less hostility from society, thus producing less pressure on individuals with this form of sexual orientation to seek psychiatric treatment. The author also states that most well-known studies are concerned with homosexuals who are patients, and that this gives a biased view point, resulting in the mistaken idea that homosexuality is a psychiatric disorder. This he claims is not so: rather, it is simply an alternative life style, most female homosexuals being well-adjusted people, representative of the population as a whole.

The first part of this book deals with the literature on this subject and is a brief review of analytical theory and studies based on patient and ron-patient samples. Homosexuality is seen by different authors as a manifestation of neurotic illness, or personality disorder, or simply a variation of normal behaviour. The study itself is essentially descriptive; it assesses the characteristics of 26 subjects. Information was obtained through the use of an extensive questionaire and telephone interviews. The purpose of the study was to test and develop the hypothesis that female homosexuality is not an illness but a way of life. On the whole, this hypothesis was confirmed, though one would have to admit that the sample was small and the subjects exhibited a selective bias, in that they were volunteers and all members of a lesbian organisation. However, the sample was well represented in relation to the population as a whole as regards religion, education, occupation and age.

The results of the personality test utilised (The Adjective Check List) revealed an overall normal pattern. In addition, individual results are given, and with one exception fall within normal limits. The majority of these people function effectively and do not feel themselves as being psychiatrically ill. As regards the etiology of this form of sexual behaviour, no significant cause or pattern could be established. However, on reviewing Dr. Rosen's test results one could identify three significant factors - these were: an impalance in the parental relationship; a distorted parent-child relationship; and the experience of the first sexual encounter.

Dr. Rosen is very definite in his opinion that homosexuality is not a psychological illness. He feels it is time that homosexuality as a mental disturbance should be deleted from the official diagnostic nomenclature of the American Psychiatric Association. He believes that psychiatrists as a whole have for too long generalised from a minority of lesbian psychiatric patients and have applied a label of "mental illness" to the whole population of female homosexuals in an illogical and unjust way.

Although one can partly agree with his view point, and certainly sympathise with the plight of the homosexual in Western society, it is difficult to accept that lesbianism is a normal phenomenon. His study simply confirms a view held by most psychiatrists that homosexua!s are capable of leading productive lives. It does nothing to disprove the generally accepted fact that homosexuality is a form of deviant sexual behaviour, and, broadly speaking, is a disorder of personality development.

KARL O'SULLIVAN.

\title{
CORRECTION
}

\section{DEMOGRAPHY OF the GeRIATRIC PROBLEM IN IRELAND}

\author{
John P. Corridan
}

On page 139 of the April 1975 issue it was stated that there were more people living in aggregate urban areas (52.6 per cent) than in aggregate rural areas (47.4 per cent) in the Republic.

These percentages should have read 52.2 and 47.8 respectively. 